\title{
Two-Dimensional TLC Separation and Mass Spectrometric Identification of Anthraquinones Isolated from the Fungus Dermocybe sanguinea
}

\author{
Riikka Räisänen ${ }^{\mathrm{a}}$, Heikki Björk ${ }^{\mathrm{b}}$, and Paavo H. Hynninen ${ }^{\mathrm{a}, *}$ \\ a Department of Chemistry, PO Box 55, University of Helsinki, FIN-00014 Helsinki, Finland. \\ Fax: +358-9-19140466. E-mail: Paavo.Hynninen@Helsinki.FI \\ b VERIFIN Institute, PO Box 55, University of Helsinki, FIN-00014 Helsinki, Finland \\ * Author for correspondence and reprint requests \\ Z. Naturforsch. 55c, 195-202 (2000); received December 20, 1999 \\ Two-Dimensional TLC, Anthraquinone, Dermocybe sanguinea \\ A new two-dimensional TLC technique was developed to separate substituted anthraqui- \\ nones on silica plates using $n$-pentanol-pyridine-methanol $(6: 4: 3, \mathrm{v} / \mathrm{v} / \mathrm{v})$ and toluene-ethyl \\ acetate-ethanol-formic acid (10:8:1:2, v/v/v/v) as eluents. The good separation power of the \\ new technique was demonstrated by applying it to the analysis of complex anthraquinone \\ mixtures isolated from the Scandinavian Dermocybe sanguinea. Emodin, physcion, en- \\ docrocin, dermolutein, dermorubin, 5-chlorodermorubin, emodin-1- $\beta$-D-glucopyranoside, \\ dermocybin-1- $\beta$-D-glucopyranoside and dermocybin, and five new, earlier in $D$. sanguinea \\ unidentified compounds, 7-chloroemodin, 5,7-dichloroemodin, 5,7-dichloroendocrocin, 4-hy- \\ droxyaustrocorticone and austrocorticone, were separated and identified on the basis of $R_{f^{-}}$ \\ values, $\mathrm{UV} / \mathrm{V}$ is spectra and mass spectra.
}

\section{Introduction}

Thin-layer chromatography has been widely used to separate various substituted anthraquinones occurring in the genera Cortinarius and Dermocybe* (Steglich et al., 1969, 1972a, 1972b; Gruber, 1970; Keller, 1982; Høiland, 1983; Keller and Ammirati, 1983; Steglich and Oertel, 1984; Kidd et al., 1985; Gill and Steglich, 1987; Keller et al., 1987). Because different species seem to possess anthraquinone compounds, that are characteristic of the species, TLC analysis of the pigments can be applied as an aid to identification and classification of these genera. The European Dermocybe -species have earlier been studied by Steglich et al. (1969, 1972a, 1972b), Gruber (1970), Keller (1982), Høiland (1983) and Kidd et al. (1985). Also Dermocybe -species occurring in America (Keller and Ammirati, 1983) and Aus-

* There is disagreement about the rank of Dermocybe in the systematical hierarchy, where it has been regarded as a subgenus of Cortinarius or a genus of its own. In chemical publications (Steglich et al., 1969, 1972a, 1972b; Gill and Steglich, 1987; Gill, 1995), Dermocybe has been regarded as a genus of its own and the same ranking is used in this article, although Scandinavian mycologists (Høiland, 1983; Brandrud et al., 1990; Ryman and Holmåsen, 1998) consider Dermocybe as a subgenus of Cortinarius. tralia (Keller et al., 1987; Gill, 1995) have been studied.

Various solvent systems have been reported for one-dimensional (1D) TLC separations of anthraquinones and other natural products occurring in fungi. In most studies (Steglich et al., 1969, 1972a, 1972b; Keller, 1982; Høiland, 1983; Keller and Ammirati, 1983; Steglich and Oertel, 1984; Kidd et al., 1985; Keller et al., 1987; Gill and Steglich, 1987; Buchanan et al., 1998) different mixtures of benzene (or toluene), ethyl formate and formic acid were used as solvent systems. Isoamylalcohol-pyridine-water $(30: 20: 15, \mathrm{v} / \mathrm{v} / \mathrm{v})$ was first used for paper chromatography (Gruber, 1970) and the solvent system was modified later for cellulose TLC replacing isoamylalcohol with $n$-butanol (Keller, 1982; Keller et al., 1987). Nevertheless, we found the existing 1D TLC methods to have limited potentiality in separating samples containing several anthraquinone derivatives in very different ratios, because some of the derivatives overlapped one another partially or completely. Though two-dimensional (2D) TLC has been used to separate anthracene compounds (Zwaving, 1980), we found no reports about separations of fungal or other natural quinone compounds by $2 \mathrm{D}$ TLC. This prompted us to develop 2D TLC techniques to obtain more distinct and satisfactory sep- 
arations for anthraquinone derivatives isolated from Dermocybe sanguinea.

In this study, five new and nine previously identified anthraquinones were found to occur in the Scandinavian $D$. sanguinea. The new compounds were 7-chloroemodin (3), 5,7-dichloroemodin (4), 5,7-dichloroendocrocin (6), 4-hydroxyaustrocorticone (11) and austrocorticone (12) and the compounds previously identified by Steglich et al. (1969, 1972a) were emodin (1), physcion (2), endocrocin (5), dermolutein (7), dermorubin (8), 5-chlorodermorubin (9), emodin-1- $\beta$-D-glucopyranoside (13), dermocybin-1- $\beta$ D-glucopyranoside (14) and dermocybin (15) (structures of the compounds are shown in Fig. 1). Emodin- and dermocybin-glycosides were the main pigments, whereas some of the pigments, e.g. the five new compounds, existed in very small quantities. After separation by $2 \mathrm{D}$ TLC, the pigments were tentatively identified on the basis of the $\mathrm{R}_{\mathrm{f}}$-values and colours observed on silica TLC plates under visible and UV light. The anthraquinone derivatives were more con-

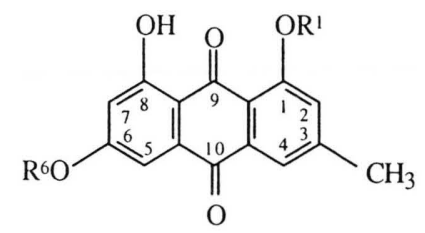

\begin{tabular}{lll}
\hline $\mathrm{R}^{1}$ & $\mathrm{R} 6$ & Compound (no) \\
\hline $\mathrm{H}$ & $\mathrm{H}$ & Emodin (1) \\
$\mathrm{Glu}$ & $\mathrm{H}$ & Emodin-1- $\beta-D-G l u c p ~(13)$ \\
$\mathrm{H}$ & $\mathrm{CH}_{3}$ & Physcion (2) \\
\hline
\end{tabular}<smiles>[R20]Oc1cc(C)cc2c1C(=O)c1c(O)c([R])c([R2])c(O)c1C2=O</smiles>

\begin{tabular}{lllll}
\hline $\mathrm{R}^{1}$ & $\mathrm{R}^{5}$ & $\mathrm{R}^{6}$ & $\mathrm{R}^{7}$ & Compound (no) \\
\hline $\mathrm{H}$ & $\mathrm{H}$ & $\mathrm{H}$ & $\mathrm{Cl}$ & 7-Chloroemodin (3) \\
$\mathrm{H}$ & $\mathrm{Cl}$ & $\mathrm{H}$ & $\mathrm{Cl}$ & 5,7-Dichloroemodin (4) \\
$\mathrm{H}$ & $\mathrm{H}$ & $\mathrm{CH}_{3}$ & $\mathrm{OH}$ & Dermoglausin \\
$\mathrm{H}$ & $\mathrm{OH}$ & $\mathrm{CH}_{3}$ & $\mathrm{OH}$ & Dermocybin (15) \\
$\mathrm{Glu}$ & $\mathrm{OH}$ & $\mathrm{CH}_{3}$ & $\mathrm{OH}$ & Dermocybin-1- $\beta-D-G l u c p(14)$ \\
\hline
\end{tabular}

clusively identified by UV/Vis and mass spectrometric measurements. For the measurements, the compounds were first prefractionated using preparative multiple liquid-liquid partition (MartinSynge distribution, MSD, Hynninen, 1976) and then more thoroughly purified by preparative 1D and 2D TLC on silica plates using the solvent systems described below.

We were interested in fungal anthraquinones because of their bright colours. Our aim was, besides the separation and identification of the anthraquinone compounds in $D$. sanguinea, to extract and purify these compounds in a large scale and apply them as dyes for textile materials. The results from our dyeing experiments will be reported later. In this paper, we will show that several anthraquinone compounds can easily be separated completely from one another by $2 \mathrm{D}$ TLC using $n$-pentanol-pyridine-methanol, 6:4:3, v/v/v (PPM) as solvent system I and toluene-ethyl acetate-ethanol-formic acid, 10:8:1:2, v/v/v/v (TEEF) as solvent system II, respectively. This technique has several advantages compared with 1D TLC<smiles>[R]c1c(C(C)=O)c(C(=O)O)c(O)c2c1C(=O)c1cc(OC)cc(OC)c1C2=O</smiles>

\begin{tabular}{ll}
\hline $\mathrm{R}^{4}$ & Compound (no) \\
\hline $\mathrm{H}$ & Austrocorticone (12) \\
$\mathrm{OH}$ & 4-Hydroxyaustrocorticone (11) \\
\hline
\end{tabular}<smiles>[R]c1c([R2])c2c(c([R])c1O)C(=O)c1c(O)c(C(=O)O)c(C)c([R])c1C2=O</smiles>

\begin{tabular}{lllll}
\hline $\mathrm{R}^{4}$ & $\mathrm{R}^{5}$ & $\mathrm{R}^{7}$ & $\mathrm{R}^{8}$ & Compound (no) \\
\hline $\mathrm{H}$ & $\mathrm{H}$ & $\mathrm{H}$ & $\mathrm{H}$ & Endocrocin (5) \\
$\mathrm{H}$ & $\mathrm{Cl}$ & $\mathrm{Cl}$ & $\mathrm{H}$ & 5,7-Dichloroendocrocin (6) \\
$\mathrm{H}$ & $\mathrm{H}$ & $\mathrm{H}$ & $\mathrm{CH}_{3}$ & Dermolutein (7) \\
$\mathrm{H}$ & $\mathrm{Cl}$ & $\mathrm{H}$ & $\mathrm{CH}_{3}$ & 5-Chlorodermolutein \\
$\mathrm{OH}$ & $\mathrm{H}$ & $\mathrm{H}$ & $\mathrm{CH}_{3}$ & Dermorubin (8) \\
$\mathrm{OH}$ & $\mathrm{Cl}$ & $\mathrm{H}$ & $\mathrm{CH}_{3}$ & 5-Chlorodermorubin (9) \\
\hline
\end{tabular}

Fig. 1. Structures of the anthraquinone compounds and their numbers on the two-dimensional TLC plate. Glucp $=$ glucopyranoside. 
and can offer a simple aid for mycologists in their chemotaxonomic studies as well.

\section{Experimental}

\section{Materials}

A new enzymatic method, described in details elsewhere (Hynninen et al., in preparation), was developed to isolate the anthraquinone aglycones from the fruit bodies of the fungus $D$. sanguinea. In the method, the endogenous $\beta$-glucosidase [EC 3.2.1.21, $\beta$-D-glucoside glucohydrolase] of the fungus was used to catalyze the hydrolysis of the $O$ glycosyl linkage in emodin- and dermocybin- $1-\beta$ D-glucopyranosides. The method yielded two fractions: fraction 1 containing mainly emodin and dermocybin and fraction 2 containing the hydroxyanthraquinone carboxylic acids as well as small amounts of residual emodin- and dermocybin- $1-\beta$ D-glucopyranosides.

\section{Chemicals}

All chemicals, if not mentioned otherwise, were of analytical-reagent grade. Toluene, chloroform, formic acid and $n$-pentanol were purchased from E. Merck (Darmstadt, Germany), isopropylmethyl ketone from Fluka AG (Buchs, Switzerland) and pyridine and acetic anhydride from Riedel-de Haen AG (Seelze, Germany). AaS-grade ethanol was purchased from Primalco (Rajamäki, Finland). Ammonium acetate, ethyl acetate and methanol, all HPLC-grade, were purchased from Lab-Scan (Dublin, Ireland). Aluminum sheets or glass plates $(20 \mathrm{~cm} \times 20 \mathrm{~cm} \times 0.2 \mathrm{~cm})$ precoated with silica gel 60 without fluorescent indicator (E. Merck, Darmstadt, Germany) were used for TLC.

\section{Instrumentation}

A CAMAG UV-cabinet II was used for UV detection at the wavelength of $366 \mathrm{~nm}$. The UV/Vis spectra were measured using a Varian Cary $5 \mathrm{E}$ UV-Vis-NIR spectrophotometer (Varian Optical Spectroscopy Instruments, Mulgrave, Victoria, Australia) and Hellma Suprasil quartz-glass microcuvettes of type 115B-QS with a pathlength $10 \mathrm{~mm}$ (Hellma, Germany). The positive-ion electron impact mass spectra (EI) were measured on a JEOL JMS-SX 102 mass spectrometer (JEOL, Tokyo, Japan) working at the following tuning parameters: electron energy $70 \mathrm{eV}$, emission current $200 \mathrm{~mA}$ and source temperature $240{ }^{\circ} \mathrm{C}$. LC-MS and LCMS/MS analyses were performed with a Micromass Quattro II triple stage quadrupole mass spectrometer (Micromass, Manchester, UK) equipped with an electrospray (ES) probe. In LC, a 1:1 (v/ v) mixture of ammonium acetate $(20 \mathrm{~mm}, \mathrm{pH} 8.5)$ and methanol was used as the mobile phase at flow rate $0.1 \mathrm{ml} / \mathrm{min}$. Methanol solutions $(20 \mu \mathrm{l})$ of the analytes were introduced into the LC using a Merck Hitachi L-6200A pump equipped with the Rheodyne loop injector. Negative ion spectra were produced under the following conditions: source temperature $80^{\circ} \mathrm{C}$, capillary voltage $3.0 \mathrm{kV}$ and cone voltage $20 \mathrm{~V}$. High purity nitrogen was used as a drying gas and a nebulising gas at flow rates $250 \mathrm{l} / \mathrm{h}$ and $20 \mathrm{l} / \mathrm{h}$, respectively. To produce CAD (collision activated dissociation) spectra of [M$\mathrm{H}]^{-}$parent ions, collision energy $\left(\mathrm{E}_{\mathrm{col}}\right)$ of 20,25 or $35 \mathrm{eV}$ and a collision gas (argon) pressure of $1.1 \times 10^{-3}$ mbar were used.

\section{TLC separations}

Two glass chambers with internal dimensions of $21 \mathrm{~cm} \times 9 \mathrm{~cm} \times 24 \mathrm{~cm}$ were used for TLC. The inner walls of the chambers were lined with filter paper Whatman No. 1 (Whatman, Maidstone, England). A fixed volume $(200 \mathrm{ml})$ of eluent was poured into each chamber and the atmospheres were allowed to stabilize. The sample solution for TLC was prepared by dissolving a small amount of fraction 1 or 2 in an appropriate volume of ethanol to give a transparent solution.

For 1D TLC, suitable aliquots of the sample solutions were spotted onto a TLC plate $(6 \mathrm{~cm} \times 20$ $\mathrm{cm}) 2 \mathrm{~cm}$ away from the lower edge of the plate and $2 \mathrm{~cm}$ away from one another. The plate was placed into the TLC chamber containing PPM or TEEF as solvent system and the solvent front was allowed to rise until it was about $2 \mathrm{~cm}$ from the upper edge. The line of the solvent front was marked and the plate was allowed to dry.

For 2D TLC, aliquots of the sample solution were spotted to one corner of the TLC plate, $2 \mathrm{~cm}$ away from the closest edges. The plate was developed in the first direction in the TLC chamber containing PPM as solvent system I until the solvent front was about $2 \mathrm{~cm}$ from the upper edge. The line of the solvent front was marked and the drying of the plate was accelerated with the aid of 
a hand-held dryer. The plate was turned $90^{\circ}$ and developed in the second direction with TEEF as solvent system II. The dried plates were viewed under visible and ultraviolet light $(366 \mathrm{~nm})$.

\section{Preparative prefractionations by Martin-Synge distribution}

To obtain sufficient amounts of the compounds pure enough for MS characterization, the anthraquinone derivatives in fractions 1 and 2, were preparatively prefractionated by the MSD technique (Hynninen and Räisänen, in preparation). In the MSD fractionations, isopropylmethyl ketone was used as the stationary upper phase and sodium phosphate buffer as the mobile lower phase, taking advantage of the stepwise $\mathrm{pH}$-gradient elution (Hynninen, 1973a, 1973b). After the MSD fractionation, the final purifications of the compounds were accomplished by preparative 1D and 2D TLC using the PPM and TEEF solvent systems.

\section{Acetylation of the anthraquinone glycosides}

For the acetylation of the $\mathrm{OH}$-groups, the sample was dissolved in pyridine (dried over $4 \AA$ molecular sieves) and an excess of acetic anhydride was added. The mixture was allowed to react overnight at room temperature. The reaction mixture was then poured into water and the precipitated anthraquinone glucopyranosyl acetate was extracted into chloroform in a separatory funnel. The chloroform phase was collected and evaporated to dryness.

\section{Results and Discussion}

\section{$T L C$ results}

1D TLC separations showed that neither an acidic nor a basic solvent system alone separated completely all the anthraquinone compounds isolated from $D$. sanguinea, in spite of the variation of the ratios of the solvent components in the systems. Thus, using the TEEF solvent system, most anthraquinone compounds were resolved quite satisfactorily, but dermolutein, dermorubin and 5chlorodermorubin from fraction 2 migrated together and were observed as one spot. To be able to resolve also the three last-mentioned compounds, we elaborated the PPM system, to be used as solvent system I in 2D TLC. With the PPM system, 5-chlorodermorubin moved markedly slower than dermorubin and dermolutein and was thus separated.

Figure 2 shows the separation of fifteen anthraquinone compounds by 2D TLC using PPM

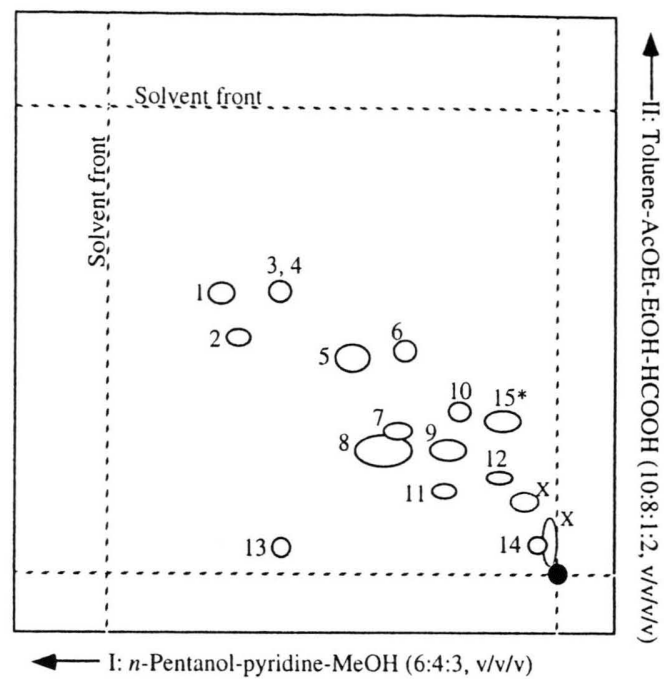

\begin{tabular}{lllll}
\hline Anthraquinone compound (no) & $\begin{array}{l}\mathrm{R}_{\mathrm{f}} \\
\mathrm{I}\end{array}$ & $\begin{array}{l}\mathrm{R}_{\mathrm{f}} \\
\mathrm{II}\end{array}$ & $\begin{array}{l}\text { Colour } \\
\text { Vis }\end{array}$ & $\begin{array}{l}\text { Colour } \\
\mathrm{UV}\end{array}$ \\
\hline Emodin (1) & 0.79 & 0.62 & yellow & yellow \\
Physcion (2) & 0.73 & 0.52 & yellow & red \\
7-Chloroemodin (3) and & 0.60 & 0.64 & yellow & red \\
5,7-dichloroemodin (4) & & & & \\
Endocrocin (5) & 0.45 & 0.48 & yellow & orange \\
5,7-Dichloroendocrocin (6) & 0.31 & 0.49 & red & red \\
Dermolutein (7) & 0.37 & 0.31 & yellow & orange \\
Dermorubin (8) & 0.37 & 0.27 & red & orange \\
5-Chlorodermorubin (9) & 0.24 & 0.28 & rosa & rosa \\
Unidentified (10) & 0.20 & 0.36 & brown & yellow-green \\
4-Hydroxyaustrocorticone (11) & 0.26 & 0.19 & red & orange-red \\
Austrocorticone (12) & 0.13 & 0.23 & yellow & yellow-green \\
Emodin-1- $\beta$-D-Glucp (13) & 0.69 & 0.13 & yellow & yellow \\
Dermocybin-1- $\beta$-D-Glucp (14) & 0.04 & 0.08 & red & red \\
Dermocybin (15) & 0.10 & 0.38 red & red \\
\hline
\end{tabular}

Fig. 2. A $2 \mathrm{D}$ thin-layer chromatogram and the $\mathrm{R}_{\mathrm{f}}$-values and colours for the spots of the anthraquinone compounds in D. sanguinea using PPM and TEEF as solvent systems. Structures of the compounds are shown in Fig. 1. Sizes of the spots are not comparable with the amounts of the compounds. * = compound observed only in fraction 1. $\mathrm{X}=$ nonanthraquinone compounds (possibly cortinarins (Caddy et al., 1982; Tebbett and Caddy, 1984)) observed only as blue fluorescence under UV-light. 
as the first and TEEF as the second solvent system. 2D TLC was also run with the solvent systems in the reverse order. In this reversed-order experiment, the resolution of the compounds was not as clear; the compounds remained closer to one another in the middle of the plate and more tailing was observed.

All the compounds shown in Fig. 2 except dermocybin (15) were observed in fraction 2. Emodin (1), dermocybin (15) and very small amounts of

Table I. UV/Vis and mass spectra of the anthraquinones in D. sanguinea.

\begin{tabular}{|c|c|c|c|}
\hline $\begin{array}{l}\text { Compound } \\
\text { (no) }\end{array}$ & $\begin{array}{l}\text { Molecular } \\
\text { formula }\end{array}$ & $\begin{array}{l}\text { UV/Vis } \\
\lambda_{\max }[\mathrm{nm}] \text { (peak ratios) }\end{array}$ & $\begin{array}{l}\text { MS data } \\
m / z\end{array}$ \\
\hline $\begin{array}{l}\text { Emodin } \\
\text { (1) }\end{array}$ & $\begin{array}{l}\mathrm{C}_{15} \mathrm{O}_{5} \mathrm{H}_{10} \\
(270.0528)\end{array}$ & $\begin{array}{l}219(1), 254(0.61), 264(0.55) \\
291(0.62), 438(0.35), 455 \mathrm{sh} \\
(0.34) \text { in EtOH }\end{array}$ & $\begin{array}{l}\text { ES: } 269[\mathrm{M}-\mathrm{H}]^{-} ; \text {ES/CAD }\left(\mathrm{E}_{\mathrm{col}} 25 \mathrm{eV}\right): 269(100 \%)[\mathrm{M}-\mathrm{H}]^{-}, 241 \\
(20)[\mathrm{M}-\mathrm{H}-\mathrm{CO}]^{-}, 225(20)\left[\mathrm{M}-\mathrm{H}-\mathrm{CO}-\mathrm{O}^{-} \text {; EI: } 270(100 \%) \mathrm{M}^{+},\right. \\
241(5)[\mathrm{M}-\mathrm{CHO}]^{+}, 213(4)[\mathrm{M}-\mathrm{CHO}-\mathrm{CO}]^{+}, 121(5) .\end{array}$ \\
\hline $\begin{array}{l}\text { Physcion } \\
\text { (2) } \\
\text { 7-Chloro- } \\
\text { emodin } \\
\text { (3) }\end{array}$ & $\begin{array}{l}\mathrm{C}_{16} \mathrm{O}_{5} \mathrm{H}_{12} \\
(284.0685) \\
\mathrm{C}_{15} \mathrm{O}_{5} \mathrm{H}_{9} \mathrm{Cl} \\
(304.0139)\end{array}$ & $\begin{array}{l}222(1), 283(0.53), 431(0.25) \text { in } \\
\text { EtOH } \\
245(0.83), 251(0.95), 257(1), \\
263(0.85), 306(0.37), 436 \\
(0.21), 453 \text { sh }(0.21), 516 \text { sh } \\
(0.10) \text { in } \mathrm{MeOH}\end{array}$ & $\begin{array}{l}\text { ES: } 283[\mathrm{M}-\mathrm{H}]^{-} ; \mathrm{ES} / \mathrm{CAD}\left(\mathrm{E}_{\mathrm{col}} 20 \mathrm{eV}\right): 283(100 \%)[\mathrm{M}-\mathrm{H}]^{-}, 268 \\
\text { (2) }\left[\mathrm{M}-\mathrm{H}-\mathrm{CH}_{3}\right]^{-}, 240(46)[\mathrm{M}-\mathrm{H}-\mathrm{COCH}]_{3}^{-} \\
\text {ES: } 305\left[{ }^{37} \mathrm{Cl} \mathrm{M}-\mathrm{H}\right]^{-} \text {and } 303\left[{ }^{35} \mathrm{Cl} \mathrm{M}-\mathrm{H}\right]^{-} ; \mathrm{ES} / \mathrm{CAD}\left(\mathrm{E}_{\mathrm{col}} 25 \mathrm{eV}\right) \text { : } \\
303(100 \%)[\mathrm{M}-\mathrm{H}]^{-}, 287(5)[\mathrm{M}-\mathrm{H}-\mathrm{O}]^{-}, 275(4)[\mathrm{M}-\mathrm{H}-\mathrm{CO}]^{-}, \\
267(6)[\mathrm{M}-\mathrm{H}-\mathrm{HCl}]^{-}, 259(6), 239(64)[\mathrm{M}-\mathrm{H}-\mathrm{HCl}-\mathrm{CO}]^{-}, 211 \\
(60) .\end{array}$ \\
\hline $\begin{array}{l}5,7 \text {-Dichloro- } \\
\text { emodin } \\
\text { (4) }\end{array}$ & $\begin{array}{l}\mathrm{C}_{15} \mathrm{O}_{5} \mathrm{H}_{8} \mathrm{Cl}_{2} \\
(337.9749)\end{array}$ & $\begin{array}{l}260(1), 319(0.85), 436 \text { sh } \\
(0.29), 467 \text { sh }(0.33), 497(0.37) \\
\text { in MeOH }\end{array}$ & $\begin{array}{l}\mathrm{ES}: 339\left[{ }^{37} \mathrm{Cl} \mathrm{M}-\mathrm{H}\right]^{-} \text {and } 337\left[{ }^{35} \mathrm{Cl} \mathrm{M}-\mathrm{H}^{-}, \text {ES/CAD }\left(\mathrm{E}_{\mathrm{col}} 25 \mathrm{eV}\right) \text { : }\right. \\
337(100 \%)[\mathrm{M}-\mathrm{H}]^{-}, 309(10)[\mathrm{M}-\mathrm{H}-\mathrm{CO}]^{-}, 293(3), 273(11)[\mathrm{M}- \\
\mathrm{H}-\mathrm{CO}-\mathrm{HCl}]^{-}, 265(13), 257(2), 245(13), 237(9)[\mathrm{M}-\mathrm{H}-\mathrm{CO}-2 \\
\mathrm{HCl}^{-}, 209(4), 181(3), 35(4) \mathrm{Cl}^{-} \text {. }\end{array}$ \\
\hline $\begin{array}{l}\text { Endocrocin } \\
(\mathbf{5})\end{array}$ & $\begin{array}{l}\mathrm{C}_{16} \mathrm{O}_{7} \mathrm{H}_{10} \\
(314.0427)\end{array}$ & $\begin{array}{l}258(1), 263(0.94), 275(0.74), \\
313(0.38), 442(0.39) \text { in EtOH }\end{array}$ & $\begin{array}{l}\text { ES: } 313[\mathrm{M}-\mathrm{H}]^{-} ; \text {ES/CAD }\left(\mathrm{E}_{\mathrm{col}} 35 \mathrm{eV}\right): 313(5 \%)[\mathrm{M}-\mathrm{H}]^{-}, 269 \\
(65)\left[\mathrm{M}-\mathrm{H}-\mathrm{CO}_{2}\right]^{-}, 240(45)\left[\mathrm{M}-\mathrm{H}-\mathrm{CO}_{2}-\mathrm{CHO}\right]^{-}, 225(54)[\mathrm{M}- \\
\left.\mathrm{H}-\mathrm{CO}_{2}-\mathrm{CO}-\mathrm{O}\right]^{-}, 195(100), 182(85) .\end{array}$ \\
\hline $\begin{array}{l}\text { 5,7-Dichloro- } \\
\text { endocrocin } \\
\text { (6) }\end{array}$ & $\begin{array}{l}\mathrm{C}_{16} \mathrm{O}_{7} \mathrm{H}_{8} \mathrm{Cl}_{2} \\
(381.9647)\end{array}$ & $\begin{array}{l}222(1), 262(0.78), 321(0.82) \text {, } \\
500(0.41) \text { in } \mathrm{MeOH}\end{array}$ & ES: $383\left[{ }^{37} \mathrm{Cl} \mathrm{M}-\mathrm{H}\right]^{-}$and $381\left[{ }^{35} \mathrm{Cl} \mathrm{M}-\mathrm{H}\right]^{-}$ \\
\hline $\begin{array}{l}\text { Dermolutein } \\
\text { (7) }\end{array}$ & $\begin{array}{l}\mathrm{C}_{17} \mathrm{O}_{7} \mathrm{H}_{12} \\
(328.0583)\end{array}$ & $427 \mathrm{sh}, 432,443 \mathrm{sh}$ in $\mathrm{EtOH} *$ & $\begin{array}{l}\mathrm{ES}: 327[\mathrm{M}-\mathrm{H}]^{-} ; \mathrm{ES} / \mathrm{CAD}\left(\mathrm{E}_{\mathrm{col}} 20 \mathrm{eV}\right): 327(100 \%)[\mathrm{M}-\mathrm{H}]^{-}, 283 \\
(85)\left[\mathrm{M}-\mathrm{H}-\mathrm{CO}_{2}\right]^{-}, 268(27)\left[\mathrm{M}-\mathrm{H}-\mathrm{CO}_{2}-\mathrm{CH}_{3}\right]^{-}, 240(59)[\mathrm{M}- \\
\left.\mathrm{H}-\mathrm{CO}_{2}-\mathrm{COCH}_{3}\right]^{-} \text {. }\end{array}$ \\
\hline $\begin{array}{l}\text { Dermorubin } \\
\text { (8) }\end{array}$ & $\begin{array}{l}\mathrm{C}_{17} \mathrm{O}_{8} \mathrm{H}_{12} \\
(344.0532)\end{array}$ & $\begin{array}{l}227(1), 278(0.61), 313(0.35) \\
470 \text { sh }(0.30), 481(0.32), 496 \\
(0.34), 532(0.26) \text { in EtOH }\end{array}$ & $\begin{array}{l}\text { ES: } 343[\mathrm{M}-\mathrm{H}]^{-} ; \mathrm{ES} / \mathrm{CAD}\left(\mathrm{E}_{\mathrm{col}} 20 \mathrm{eV}\right): 343(40 \%)[\mathrm{M}-\mathrm{H}]^{-}, 299 \\
(100)\left[\mathrm{M}-\mathrm{H}-\mathrm{CO}_{2}\right]^{-}, 284(3)\left[\mathrm{M}-\mathrm{H}-\mathrm{CO}_{2}-\mathrm{CH}_{3}\right]^{-}, 256(22)[\mathrm{M}- \\
\left.\mathrm{H}-\mathrm{CO}_{2}-\mathrm{COCH}_{3}\right]^{-} ; \mathrm{EI}: 344(52) \mathrm{M}^{+}, 326(56)\left[\mathrm{M}-\mathrm{H}_{2} \mathrm{O}\right]^{+}, 300 \\
(100)\left[\mathrm{M}-\mathrm{CO}_{2}\right]^{+}, 282(74)\left[\mathrm{M}-\mathrm{CO}_{2}-\mathrm{H}_{2} \mathrm{O}\right]^{+}, 254(32), 225(9), 44 \\
(100) .\end{array}$ \\
\hline $\begin{array}{l}\text { 5-Chloro- } \\
\text { dermorubin } \\
(9)\end{array}$ & $\begin{array}{l}\mathrm{C}_{17} \mathrm{O}_{8} \mathrm{H}_{11} \mathrm{Cl} \\
(378.0142)\end{array}$ & $484 \mathrm{sh}, 491 \mathrm{sh}, 505$ in $\mathrm{EtOH} *$ & $\begin{array}{l}\text { ES: } 379\left[{ }^{37} \mathrm{Cl} \mathrm{M}-\mathrm{H}\right]^{-} \text {and } 377\left[^{35} \mathrm{Cl} \mathrm{M}-\mathrm{H}\right]^{-} ; \mathrm{ES} / \mathrm{CAD}\left(\mathrm{E}_{\mathrm{col}} 20 \mathrm{eV}\right) \text { : } \\
377(75 \%)[\mathrm{M}-\mathrm{H}]^{-}, 333(100)\left[\mathrm{M}-\mathrm{H}-\mathrm{CO}_{2}\right]^{-}, 297(13)[\mathrm{M}-\mathrm{H}- \\
\left.\mathrm{CO}_{2}-\mathrm{HCl}\right]^{-}, 269(42)\left[\mathrm{M}-\mathrm{H}-\mathrm{CO}_{2}-\mathrm{HCl}-\mathrm{CO}^{-} ; \mathrm{EI}: 380(13 \%)\right. \\
{\left[{ }^{37} \mathrm{Cl} \mathrm{M}\right]^{+}, 378(30) \mathrm{M}^{+}, 360(40)\left[\mathrm{M}-\mathrm{H}_{2} \mathrm{O}\right]^{+}, 334(31)\left[\mathrm{M}-\mathrm{CO}_{2}\right]^{+} \text {, }} \\
332(31)\left[\mathrm{M}-\mathrm{H}_{2} \mathrm{O}-\mathrm{CO}\right]^{+}, 298(53)\left[\mathrm{M}-\mathrm{CO}_{2}-\mathrm{Cl}\right]^{+}, 270(26), 41 \\
(14), 44(100), 36(7) .\end{array}$ \\
\hline $\begin{array}{l}\text { Unidentified } \\
\text { (10) }\end{array}$ & & $\begin{array}{l}214(1), 251(0.73), 307(0.55), \\
362(0.18) \text { in } \mathrm{MeOH}\end{array}$ & $\begin{array}{l}\mathrm{ES}: 329[\mathrm{M}-\mathrm{H}]^{-} ; \mathrm{ES} / \mathrm{CAD}\left(\mathrm{E}_{\mathrm{col}} 25 \mathrm{eV}\right): 285(26 \%)\left[\mathrm{M}-\mathrm{H}-\mathrm{CO}_{2}\right]^{-} \text {, } \\
270(100)\left[\mathrm{M}-\mathrm{H}-\mathrm{CO}_{2}-\mathrm{CH}_{3}\right]^{-}, 241 \quad(6)\left[\mathrm{M}-\mathrm{H}-\mathrm{CO}_{2}-\mathrm{CH}_{3}-\right. \\
\mathrm{CHO}]^{-}, 226(85)\left[\mathrm{M}-\mathrm{CO}_{2}-\mathrm{CH}_{3}-\mathrm{CHOCH}_{3}\right]^{-} .\end{array}$ \\
\hline $\begin{array}{l}\text { 4-Hydroxy- } \\
\text { austrocorticone } \\
\text { (11) }\end{array}$ & $\begin{array}{l}\mathrm{C}_{19} \mathrm{O}_{9} \mathrm{H}_{14} \\
(386.0638)\end{array}$ & $\begin{array}{l}229 \mathrm{sh}(1), 240 \mathrm{sh}(0.95), 303 \mathrm{sh} \\
(0.69), 317(0.72), 437 \mathrm{sh}(0.26), \\
512(0.34), 534 \text { sh }(0.34) \text { in } \\
\mathrm{MeOH}\end{array}$ & $\begin{array}{l}\text { ES: } 385[\mathrm{M}-\mathrm{H}]^{-} ; \mathrm{ES} / \mathrm{CAD}\left(\mathrm{E}_{\mathrm{col}} 25 \mathrm{eV}\right): 385(25 \%)[\mathrm{M}-\mathrm{H}]^{-}, 341 \\
\text { (11) }\left[\mathrm{M}-\mathrm{H}-\mathrm{CO}_{2}\right]^{-}, 326(10)\left[\mathrm{M}-\mathrm{H}-\mathrm{CO}_{2}-\mathrm{CH}_{3}\right]^{-}, 323(100)[\mathrm{M}- \\
\left.\mathrm{H}-\mathrm{CO}_{2}-\mathrm{H}_{2} \mathrm{O}\right]^{-}, 308(78)\left[\mathrm{M}-\mathrm{H}-\mathrm{CO}_{2}-\mathrm{H}_{2} \mathrm{O}-\mathrm{CH}_{3}\right]^{-}, 298(17) \\
{\left[\mathrm{M}-\mathrm{H}-\mathrm{CO}_{2}-\mathrm{COCH}_{3}\right]^{-} .}\end{array}$ \\
\hline $\begin{array}{l}\text { Austrocorticone } \\
\text { (12) }\end{array}$ & $\begin{array}{l}\mathrm{C}_{19} \mathrm{O}_{8} \mathrm{H}_{14} \\
(370.0689)\end{array}$ & $\begin{array}{l}244(1), 311(0.1), 469(0.03) \text { in } \\
\text { MeOH }\end{array}$ & ES: $369[\mathrm{M}-\mathrm{H}]^{-}$ \\
\hline $\begin{array}{l}\text { Emodin- } \\
1-\beta-\mathrm{D}-\text { Glucp } \\
(\mathbf{1 3})\end{array}$ & $\begin{array}{l}\mathrm{C}_{21} \mathrm{O}_{10} \mathrm{H}_{20} \\
(432.1056)\end{array}$ & $\begin{array}{l}250(1), 265(0.85), 285(1), 421 \\
(0.38) \text { in } \mathrm{MeOH}\end{array}$ & $\begin{array}{l}\text { Emodin-1- } \beta \text {-D-Glucp heksaacetate, EI: } 684(1 \%) \mathrm{M}^{+}, 642(1)[\mathrm{M}- \\
\mathrm{Ac}^{+}, 354(20)[\text { aglycone }]^{+}, 331(29)[\mathrm{Gluc} p \text { tetraacetate }]^{+}, 312(17) \\
{\left[\text { aglycone }-\mathrm{Ac}^{+}, 288(5), 270(100) \text { [aglycone }-2 \mathrm{Ac}\right]^{+}, 241(6)} \\
\text { [aglycone }-2 \mathrm{Ac}-\mathrm{CHO}]^{+}, 213(4) \text { [aglycone }-2 \mathrm{Ac}-\mathrm{CHO}- \\
\mathrm{CO}]^{+}, 169(40), 126(10), 109(19), 98(32), 81(4), 60(13), 43(86) .\end{array}$ \\
\hline $\begin{array}{l}\text { Dermocybin- } \\
1-\beta \text {-D-Glucp } \\
\text { (14) }\end{array}$ & $\begin{array}{l}\mathrm{C}_{22} \mathrm{O}_{12} \mathrm{H}_{22} \\
(478.1111)\end{array}$ & $\begin{array}{l}262(1), 364(0.19), 483(0.33), \\
520 \text { sh }(0.20) \text { in } \mathrm{MeOH}\end{array}$ & $\begin{array}{l}\text { Dermocybin-1- } \beta \text {-D-Glucp heptaacetate, EI: } 770(1 \%)[\mathrm{M}-2 \mathrm{H}]^{+}, \\
728(2)[\mathrm{M}-2 \mathrm{H}-\mathrm{Ac}]^{+}, 686(2)[\mathrm{M}-2 \mathrm{H}-2 \mathrm{Ac}]^{+}, 442(2)[\text { aglycone }]^{+}, \\
400(7) \text { [aglycone }-\mathrm{Ac}]^{+}, 358(19)\left[\text { aglycone }-2 \mathrm{Ac}^{+}, 331(56)\right. \\
\left.\left[\mathrm{Glucp}^{+} \text {tetraacetate }\right]^{+}, 316(61) \text { [aglycone }-3 \mathrm{Ac}\right]^{+}, 300(11), 288 \\
(6), 270(40), 169(87), 126(13), 109(36), 98(29), 81(5), 60(7), 43 \\
(100) .\end{array}$ \\
\hline $\begin{array}{l}\text { Dermocybin } \\
\text { (15) }\end{array}$ & $\begin{array}{l}\mathrm{C}_{16} \mathrm{O}_{7} \mathrm{H}_{12} \\
(316.0583)\end{array}$ & $\begin{array}{l}218(1), 264(0.62), 282(0.63) \\
350(0.24), 460 \text { sh }(0.33), 486 \\
(0.37), 521(0.30) \text { in } \mathrm{MeOH}\end{array}$ & $\begin{array}{l}\text { EI: } 316(100 \%) \mathrm{M}^{+}, 298(11)\left[\mathrm{M}-\mathrm{H}_{2} \mathrm{O}\right]^{+}, 287(3)[\mathrm{M}-\mathrm{CHO}]^{+}, 270 \\
\text { (22) }\left[\mathrm{M}-\mathrm{H}_{2} \mathrm{O}-\mathrm{CO}\right]^{+}, 269(3), 258(4), 245(17) .\end{array}$ \\
\hline
\end{tabular}

$* \lambda_{\max }$ in UV could not be obtained due to impurities in that region. 
physcion (2), endocrocin (5) and dermorubin (8) were the components in fraction 1 . The $\mathrm{R}_{\mathrm{f}}$-values of the anthraquinone compounds for the PPM and TEEF solvent systems and the observed colours of the compounds are listed in Fig. 2. The UV/Vis and MS data are compiled in Table I.

\section{Identification of the anthraquinone compounds}

We were able to isolate and identify fourteen different anthraquinone derivatives from the Scandinavian $D$. sanguinea. Nine of these are the same as those reported by Steglich et al. (1969, 1972a) to occur in D. sanguinea or D. semisanguinea: emodin (1), physcion (2), endocrocin (5), dermolutein (7), dermorubin (8), 5-chlorodermorubin (9), emodin-1- $\beta$-D-glucopyranoside (13), dermocybin-1- $\beta$-D-glucopyranoside (14) and dermocybin (15). In addition to these, Steglich et al. $(1969,1972 a)$ reported the occurrence of dermoglausin and 5-chlorodermolutein (Fig. 1) in the European Dermocybe-species. It is possible that these two compounds exist in the Scandinavian species in such small quantities that they were beyond our observation. In contrast, we isolated from the Scandinavian $D$. sanguinea small quantities of five new anthraquinone derivatives: 7 -chloroemodin (3), 5,7-dichloroemodin (4), 5,7-dichloroendocrocin (6), 4-hydroxyaustrocorticone (11) and austrocorticone (12). To our knowledge, derivatives 3, $\mathbf{4}$ and $\mathbf{6}$ have never been observed earlier in any Dermocybe-species, and derivatives $\mathbf{1 1}$ and 12 have earlier been found to occur only in an unnamed taxon within the Australian Dermocybespecies (Gill and Gimenez, 1990). Nevertheless, 7 chloroemodin, 5,7-dichloroemodin and some other chloroemodin derivatives have earlier been

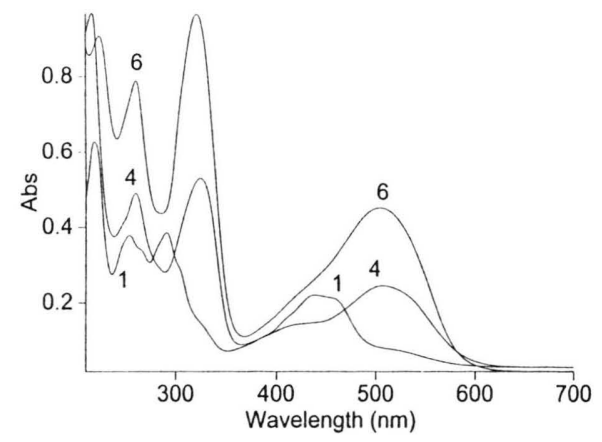

Fig. 3. UV/Vis spectra of emodin (1), 5,7-dichloroemodin (4), 5,7-dichloroendocrocin (6), dermorubin (8) and 4hydroxyaustrocorticone (11). For solvents see Table I. identified in lichen (Cohen and Towers, 1995a, 1995b, 1996).

\section{7-Chloroemodin and 5,7-dichloroemodin}

Using the modified TEEF (12:8:1:1, v/v/v/v) as solvent system in preparative 1D TLC, spot 3, 4 (Fig. 2) was resolved into two components: a red one with $\mathrm{R}_{\mathrm{f}}$-value 0.68 as the main component and a yellow one with $R_{f}$-value 0.64 . The ES spectrum of the red component exhibited an $[\mathrm{M}-\mathrm{H}]^{-}$ion peak at $\mathrm{m} / \mathrm{z} 337$ and an isotope peak at $\mathrm{m} / \mathrm{z} 339$ (intensity ratio $4: 3$ ), while the ES spectrum of the yellow component displayed the corresponding peaks at $\mathrm{m} / z 303$ and $\mathrm{m} / \mathrm{z} 305$ (intensity ratio 3:1). The ES/CAD spectrum of the $m / z 337$ ion showed losses of $\mathrm{CO}$ and two $\mathrm{HCl}$, whereas the spectrum of the $\mathrm{m} / \mathrm{z} 303$ ion showed losses of CO and one $\mathrm{HCl}$ (Table I). On the basis of the isotope ratios and the molecular mass values, which differ from that of emodin (1) by 68 and 34 mass units, the compounds of spot 3,4 were identified as dichloroemodin and chloroemodin, respectively. Further evidence for this identification was obtained by comparing the UV/Vis-spectral data of the compounds M 338 and M 304 with those of emodin. Clear bathochromic shifts were observed in the absorption bands of the chlorinated compounds relative to emodin (Fig. 3). The electronegative $\mathrm{Cl}$ substituents withdraw electron density from the anthraquinone ring, causing a bathochromic shift in the spectra. Because there are no reports of fungal anthraquinones with a $\mathrm{Cl}$-atom at position $\mathrm{C} 4$, compound M 338 was identified as 5,7-dichloroemodin (4). Our $\lambda_{\max }$-values for the red component agree with those reported for 5,7-dichloro-

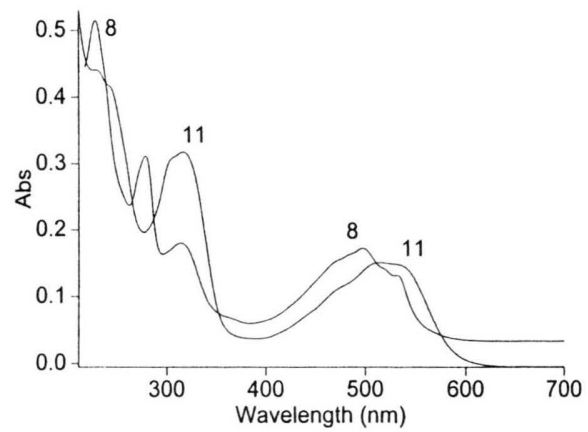
(4), 5,7-dichloroendocrocin (6), dermorubin (8) and 4- 
emodin (Cohen and Towers, 1996). We identify the yellow component as 7 -chloroemodin (3) rather than 5-chloroemodin (Fig. 1), because the UV/Vis data of the compound M 304 agree with those reported for 7-chloroemodin (Cohen and Towers, 1995a, 1995b, 1996).

\section{5,7-Dichloroendocrocin}

The component of spot 6 (Fig. 2) exhibited [M$\mathrm{H}]^{-}$ion peaks at $m / z 381$ and 383 with an intensity ratio 4:3 under the ES ionization conditions. The isotope ratio indicates that the compound possessed two $\mathrm{Cl}$-atoms. Substitution of two $\mathrm{Cl}$-atoms into endocrocin (5) gives a molecular mass value 382. The UV/Vis-spectrum of the spot 6 component is clearly red-shifted as compared with that of endocrocin (Table I) but shows close similarity to the spectrum of 5,7-dichloroemodin (Fig. 3). On the basis of these results, the spot 6 component was identified as 5,7-dichloroendocrocin (6). The results from the 2D TLC -separations (Fig. 2) show clearly that the chlorinated anthraquinones move noticeably slower in the PPM solvent system and slightly faster in the TEEF solvent system than the unchlorinated counterparts.

\section{4-Hydroxyaustrocorticone and austrocorticone}

The component of spot 11 (Fig. 2) exhibited an [M-H] $]^{-}$ion peak at $\mathrm{m} / \mathrm{z} 385$ under the ES ionization conditions. The ES/CAD spectrum of the $\mathrm{m} /$ $z 385$ ion showed fragmentations comparable with those of anthraquinone carboxylic acids: losses of $\mathrm{CO}_{2}$ and $\mathrm{H}_{2} \mathrm{O}$ were observed from the parent ion. Also losses of $\mathrm{CH}_{3}$ and $\mathrm{COCH}_{3}$ were observed (Table I). The compound M 386 was identified as 4-hydroxyaustrocorticone (11), which differs structurally from dermorubin (8) only in that dermorubin has the $3-\mathrm{CH}_{3}$ and $6-\mathrm{OH}$ groups instead of the $3-\mathrm{COCH}_{3}$ and $6-\mathrm{OCH}_{3}$ groups of 4-hydroxyaustrocorticone. Apparently, the UV/Vis-spectra of dermorubin (8) and 4-hydroxyaustrocorticone (11) resemble one another (Fig. 3), because the C3 and C6 substituents are in positions, where they do not influence markedly the $\pi$-system. However, the oxo group of the $6-\mathrm{COCH}_{3}$ substituent in 4hydroxyaustrocorticone seems to cause a slight expansion in the $\pi$-system, manifested in the bathochromic shift of the visible absorption spectrum.

The ES spectrum of a sample containing the main component of spot 12 (Fig. 2) showed two peaks at $\mathrm{m} / z 369$ and 385, which fit the molecular masses 370 and 386 of austrocorticone (12) and 4-hydroxyaustrocorticone (11) (Gill and Gimenez, 1990). Apparently the sample contained some amounts of compound $\mathbf{1 1}$ in addition to compound $\mathbf{1 2}$, as the separation of these compounds by preparative TLC was difficult. Because of the impure sample, an ES/CAD spectrum from the $[\mathrm{M}-\mathrm{H}]^{-}$ ion $\mathrm{m} / z 369$ was not available. For the TEEF solvent system, our $\mathrm{R}_{\mathrm{f}}$-values and colours for spots 11 and 12 (Fig. 2) are in agreement with those reported for 4-hydroxyaustrocorticone and austrocorticone using silica plates and the toluene-ethyl formate-formic acid (10:5:3, v/v/v) solvent system (Gill and Gimenez, 1990).

\section{Other components}

The component of spot 10 (Fig. 2) was brown under visible light and yellow-green under UVlight on the TLC plate. The UV/Vis-spectrum of the component showed absorption bands only in the UV-region which points to a reduced anthraquinone or a nonanthraquinone. The ES mass spectrum of the spot 10 component exhibited an $[\mathrm{M}-\mathrm{H}]^{-}$ion at $m / z$ 329. The ES/CAD spectrum of the ion $\mathrm{m} / \mathrm{z} 329$ showed losses of $\mathrm{CO}_{2}, \mathrm{CH}_{3}$, $\mathrm{CHO}$ and $\mathrm{CHOCH}_{3}$. The fragmentation, especially the loss of $\mathrm{CO}_{2}$, was comparable with that of anthraquinone carboxylic acids. These observations point to an anthraquinone-based structure, where one quinone oxygen or the phenyl ring was reduced. More structural information is needed for the final identification of this compound.

\section{Acknowledgements}

The authors thank the Foundation for Research of Natural Resources in Finland for financial support to this study. 
Brandrud T. E., Lindström H., Marklund H., Melot J. and Muskos S. (1990), Cortinarius Flora Photographica. Cortinarius HB, Matfors.

Buchanan M. S., Gill M. and Giménez A. (1998), New dimeric dihydroanthracenones of the flavomannin type from an Australian toadstool of the genus Dermocybe. Aust. J. Chem., 51, 103-109.

Caddy B., Kidd C. B. M., Robertson J., Tebbett I. R., Tilstone W. J. and Watling R. (1982), Cortinarius speciosissimus toxins. Experientia, 38, 1439-1440.

Cohen P. A. and Towers G. H. N. (1995a), Anthraquinones and phenanthroperylenequinones from Nephroma laevigatum. J. Nat. Prod., 58, 520-526.

Cohen P. A. and Towers G. H. N. (1995b), The anthraquinones of Heterodermia obscurata. Phytochemistry $\mathbf{4 0 ,}$ 911-915.

Cohen P. A. and Towers G. H. N. (1996), Biosynthetic studies on chlorinated anthraquinones in the lichen Nephroma laevigatum. Phytochemistry 42, 1325-1329.

Gill M. (1995), Pigments of Australasian Dermocybe Toadstools. Aust. J. Chem. 48, 1-26.

Gill M. and Gimenez A. (1990), Pigments of fungi. Part 11. (+)-Austrocorticin, austrocorticinic acid, austrocorticone, and related pigments; the first naturally occurring anthraquinones derived from a propionatetriggered octaketide. J. Chem. Soc. Perkin Trans. 1, $1159-1167$.

Gill M. and Steglich W. (1987), Pigments in fungi (Macromycetes), in: Progr. Chem. Org. Nat. Prod., Vol. 51 (Herz W., Grisebach H., Kirby G. W. and Tamm Ch., ed.). Springer-Verlag, Vienna.

Gruber I. (1970), Anthrachinonfarbstoffe in der Gattung Dermocybe und Versuch ihrer Auswertung für die Systematik. Zeitschr. f. Pilzk. 36, 95-112.

Høiland K. (1983), Cortinarius subgenus Dermocybe. Opera Botanica 71, 1-113.

Hynninen P. H. (1973a), Chlorophylls IV. Preparation and purification of some derivatives of chlorophylls $a$ and $b$. Acta Chem. Scand. 27, 1771-1780.

Hynninen P. H. and Ellfolk, N. (1973b), Use of the aqueous formic acid-chloroform-dimethylformamide solvent system for the purification of porphyrins and hemins. Acta Chem. Scand. 27, 1795-1806.
Hynninen P. H. (1976), Multiple liquid-liquid partition. II. Theory of Martin-Synge distribution (MSD). Anal. Biochem. 74, 392-404.

Keller G. (1982), Pigmentationsuntersuchungen bei europäische Arten aus der Gattung Dermocybe (Fr.) Wünsche. Sydowia 35, 110-126.

Keller G. and Ammirati J. F. (1983), Chemotaxonomic significance of anthraquinone derivatives in North American species of Dermocybe, section sanguineae. Mycotaxon 18, 357-377.

Keller G., Moser M., Horak E. and Steglich W. (1987), Chemotaxonomic investigations of species of Dermocybe (Fr. Wünsche (Agaricales)) from New Zealand, Papua New Guinea and Argentina. Sydowia 40, 168-187.

Kidd C. B. M., Caddy B., Robertson J., Tebbett I. R. and Watling R. (1985), Thin-layer chromatography as an aid for identification of Dermocybe species of Cortinarius. Trans. Br. Mycol. Soc. 85, 213-221.

Ryman S. and Holmåsen I. (1998), Svampar en fälthandbok, 3 rd rev. ed. Interpublishing, Stockholm.

Steglich W., Lösel W. and Austel V. (1969), Pilzpigmente IV. Anthrachinon-Pigmente aus Dermocybe sanguinea (Wulf. ex Fr.) Wünsche und D. semisanguinea (Fr.). Chem. Ber. 102, 4104-4118.

Steglich W. and Lösel W. (1972a), Pilzpigmente X. Anthrachinon-glucoside aus Dermocybe sanguinea (Wulf. ex Fr.) Wünsche. Chem. Ber. 105, 2928-2932.

Steglich W. and Reiniger W. (1972b), Pilzpigmente IX. Anthrachinon-Pigmente aus Dermocybe cinnabarina (Fr.) Wünsche. Chem. Ber. 105, 2922-2927.

Steglich W. and Oertel B. (1984), Untersuchungen zur Konstitution und Verbreitung der Farbstoffe von Cortinarius, Untergattung Phlegmacium (Agaricales). Sydowia 37, 284-295.

Tebbett I. R. and Caddy B. (1984), Mushroom toxins of the genus Cortinarius. Experientia 40, 441-446.

Zwaving J. H. (1980), Recent developments in the analysis of anthraquinone derivatives. Pharmacology 20, suppl. $1,65-75$. 